\title{
The Easternmost European Palaeolithic Artists: Iconography and Graphic Features at Kapova Cave (Southern Urals, Russia)
}

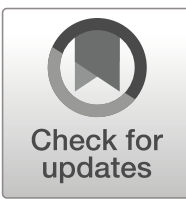

\author{
Aitor Ruiz-Redondo $^{1}$ (D) Katherin Yanovskaya ${ }^{2} \cdot$ Vladislav S. Zhitenev $^{2}$
}

Published online: 1 September 2020

(C) The Author(s) 2020

\begin{abstract}
Palaeolithic rock art is one of the most distinctive cultural traits of Upper Palaeolithic societies in Europe. Traditionally restricted to South-western Europe, especially to the Franco-Cantabrian province, in recent years, the geographic distribution of this phenomenon has noticeably expanded. Several years before these discoveries, the first decorated site found beyond southern Europe was Kapova cave, in Russia. This site, at the edge of the distribution area of European Palaeolithic art and far away from other cave sanctuaries, is key to define and understand potential long-distance cultural networks during the Upper Palaeolithic. In this paper, we present the first comprehensive inventory of the artworks, a renewed documentation of the graphic units (including the first digital tracings), the spatial distribution and the stylistic analysis of the different motifs. This led us to understand the role of Kapova within the Palaeolithic symbolism and to better integrate it in the Palaeolithic cultural dynamics.
\end{abstract}

Keywords Upper Palaeolithic · Rock art · Eastern Europe $\cdot$ Russia $\cdot$ Symbolism · Cultural transmission

\section{Introduction}

Regarding the cultural markers of Palaeolithic hunter-gatherers, symbolic behavior has a prominent role for the understanding of these societies. It has recently been arguedand proven - that humans share other traits (tool use, niche construction, complex

Aitor Ruiz-Redondo

aruizredondo@gmail.com

1 Centre for the Archaeology of Human Origins (CAHO), Department of Archaeology, University of Southampton, Southampton, UK

2 Faculty of History, Department of Archaeology, Lomonosov Moscow State University, Moscow, Russia 
social behavior, etc.) with other animal species, but symbolic language, especially on durable media, seems to be a major milestone in human uniqueness (Kuhn and Stiner 2019). Due to its relevance for the study of Palaeolithic symbolism, cave art has been in the spotlight of scholars since its very discovery and recognition (Sanz de Sautuola 1880; Cartailhac 1902). Despite this, until recently, the research has been almost exclusively focused in the renowned Franco-Cantabrian province. Nevertheless, since the beginning of the twenty-first century, new discoveries are expanding the geographic spread of Upper Palaeolithic ('UP') parietal art. Different investigations confirmed the existence of this cultural phenomenon in the UK (Bahn et al. 2003), Egypt (Huyge et al. 2007), Romania (Clottes et al. 2012), Australia (David et al. 2013), Indonesia (Aubert et al. 2014, 2018), Serbia (Ruiz-Redondo et al. 2018) and Croatia (Ruiz-Redondo et al. 2019). These discoveries have clearly demonstrated that Pleistocene rock art is a worldwide phenomenon.

Nevertheless, more than 40 years before the beginning of this series of discoveries, an UP cave art site outside the Franco-Cantabrian province was reported (Bader 1965). It is known as Kapova cave (or Shulgan-Tash in local Bashkirian language), and it is located in the Southern Urals, Russia (Fig. 1). This means that the site is over $4000 \mathrm{~km}$ as the crow flies from the easternmost Dordogne (France) cave art sites. Even in the current situation, with the abovementioned increasing number of sites discovered in different regions, the closest decorated site in the rest of Europe is over $2500 \mathrm{~km}$ distant (Coliboaia, Romania) and to island Southeast Asia (ISEA), the other major Palaeolithic cave art province claimed (Aubert et al. 2018) is over $8000 \mathrm{~km}$ away. Kapova cave remained as an 'island' for decades, until the discoveries of UP cave art in Igniatievskaya (Petrin 1997) and Serpievskaya 2 (Shirokov and Petrin 2013), both also in the Southern Urals, marked the region as its own UP parietal art province.

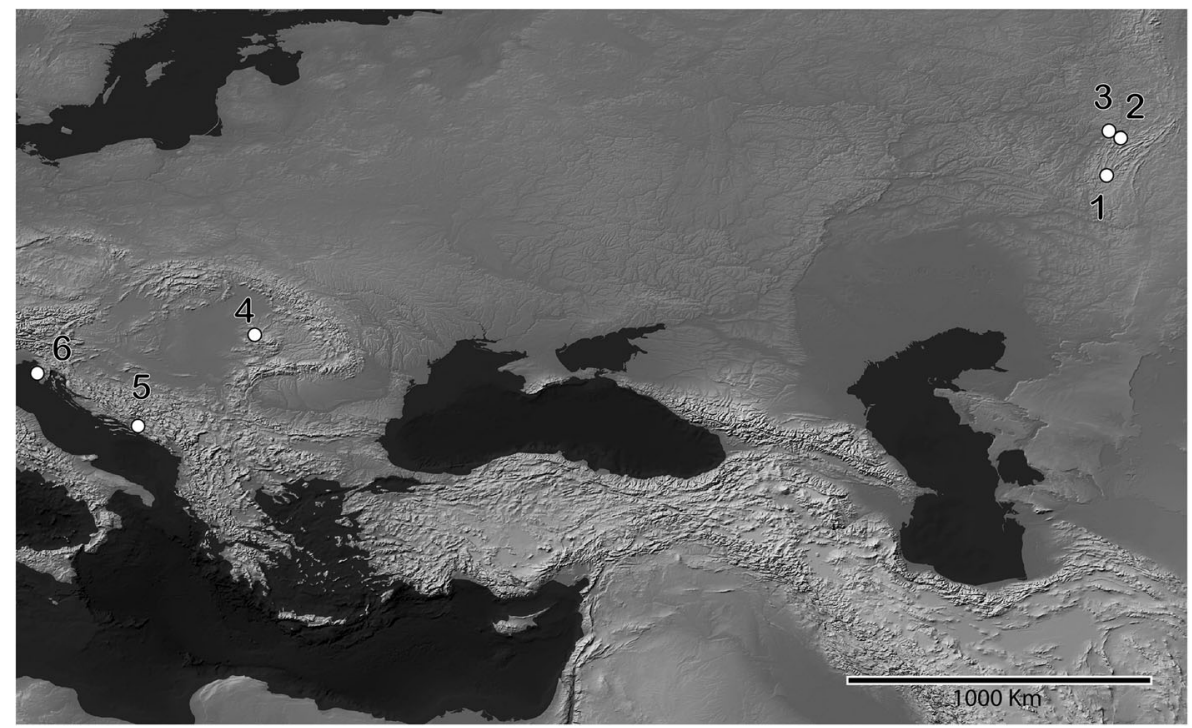

Fig. 1 Palaeolithic rock art sites in Russia and South-eastern Europe. 1, Kapova; 2, Serpievskaya 2; 3 , Igniatievskaya; 4, Coliboaia; 5, Badanj; 6, Romualdova 
Several anthropological and sociocultural questions arise regarding the integration of Kapova cave in the UP cultural mosaic. What is the relationship between this site and other decorated caves in different regions? Do the features of the graphic assemblage (iconography, techniques, style, spatial distribution and symbolic practices) link Kapova cave to other sites? Can these links help to refine the chronology of the paintings? Are they strong enough to outline potential social network routes, or is Kapova a 'unique' site? Despite a succession of archaeological projects in the site (Bader 1960-1978, Shchelinsky 1982-1991, Sherbakova 2004-2005, Kotov 2000s and Zhitenev 2008-present) and the evident archaeological interest in this rara avis of the Palaeolithic symbolism, Kapova cave's graphic assemblage is still poorly known in comparison with its 'western' pairs. Furthermore, most of its documentation needs to be renewed through up-to-date methods and technologies. In this paper, we present the first comprehensive inventory of the artworks, a renewed documentation of the graphic units (including the first digital tracings of the paintings), the spatial distribution and the stylistic analysis of the different motifs. The aim is offering an up-to-date overview of the site that led us to better integrate Kapova cave into UP cultural and social dynamics.

\section{Material and Methods}

\section{Kapova Cave: Description and Archaeological Knowledge of the Site}

Kapova cave is located on the right bank of the Belaya river in the Bashkortostan region (Southern Urals, Russia). Early explorations and descriptions of the cave were made from the eighteenth century to the first third of the twentieth century by Russian researchers such as P.I. Rychkov, I.I. Lepyokhin, F. Simon and G.V. Vakhrushev, who discovered the existence of cultural remains and palaeoanthropological materials.

In 1959, while working at the Pribelsky branch of the State Natural Bashkir Reserve, A.V. Ryumin discovered Palaeolithic paintings in Kapova cave. One year later, O.N. Bader started a series of campaigns (1960-1978) that aimed to document the rock art and its archaeological context. These led to the discovery of more than 50 paintings in both middle and upper levels, which were cleaned of modern graffiti and calcite layers. The excavations revealed other evidence of human presence during the UP in the cave (Zhitenev 2018).

During 1982-1991, V. E. Schelinsky led a comprehensive study of the cave (Shchelinsky 1987, 1990a, b, 1993, 1997, 2001; Ščelinskij and Širokov 1999). He found an interesting UP cultural layer in the Chamber of Signs, containing a significant amount of limestone blocks, lithics, faunal remains, stains and pieces of ocher, decayed remains of a tree, a bone tool, more than 150 personal ornaments (in shells, serpentinite and other materials), a block of limestone with a mammoth image and a ceramic cup. Since the beginning of the twenty-first century, during the excavations of $\mathrm{T}$. I. Shcherbakova, French restorers J. Brunet and F. Maloran have studied the preservation of the wall paintings (Zhitenev 2018).

The work of V. G. Kotov led to the discovery of the closest to the entrance area with traces of Palaeolithic human occupation (Kotov 2014). It is located in the Cascade Gallery, which connects the two levels of the cave, and yielded material from several prehistoric periods, among which some UP material is present. 
From 2008 to the present, V.S. Zhitenev (Lomonosov Moscow State University) led the 'Southern Urals archaeological expedition'. Excavations at Dome Chamber revealed several areas with archaeological remains spanning from the Holocene to the Late Pleistocene. In the Western niche (trench 1) of this chamber, the long-term series of occupations was confirmed. Up to 12 horizons of Holocene, deposits were identified (Zhitenev 2018). The ephemeral nature of the majority of these 'visits' is shown by the small amounts of archaeological material. The sole exception is the Late Bronze Age layer (Mezhovskaya culture). The discovery of human remains led to the conclusion that the niche was probably used as a burial area in the period (op. cit.). Below the Holocene layers, 9 Late Pleistocene horizons were documented. The material recovered includes a stone pavement, small fireplaces, lithics, personal ornaments and their preforms made in shell (similar to the ones discovered by Schelinsky), burnt bones, fish scales, mobiliary art (engraved marmot bones), a painted fragment of limestone and worked fragments of stalactite (op. cit.).

The documentation of the cave paintings has been essayed by different authors since the discovery. The information and the approaches diverge depending whether they come from archaeologists (O.N. Bader, V.E. Shchelinsky, V.S. Zhitenev) or amateurs (A.V. Ryumin, Y.S. Lyakhnitsky, A.K. Solodeinikov). The number of figures and their analysis present a high variability, rarely justifying the identifications of the different graphic entities or proper formal analyses.

\section{Approach to the Chronology of Kapova Cave}

A number of radiometric analyses have yielded enough results to offer an accurate chronological framework for the Kapova cave paintings. Several studies of the site revealed occupation layers in different areas, most of them linked to the rock art. During V. Shchelinsky's excavations in the Chamber of Signs, a cultural layer was documented under the panel CS.L5 (Ščelinskij and Širokov 1999). Four radiocarbon determinations were obtained from different laboratories, yielding a timespan for the occupation of ca. 19.5-16 ky cal BP (Zhitenev 2018). The relation between this layer and the art is reinforced by the discovery of a rock with a red mammoth painted on its surface. V. Kotov (2014) published three radiocarbon dates from a cultural layer found in the 'Balcony', thus not in direct connection with the paintings. Two of the results $(15,100 \pm 1300 \mathrm{BP}$ and $16,710 \pm 800 \mathrm{BP})$ yielded large standard errors (i.e. uncertainties), which question the accuracy of the pre-treatment used for the analysis. A third sample yielded a result with lower uncertainty: 13,900 \pm 190 BP. Finally, the excavations conducted at the Dome Chamber, below the panel DC.L3, revealed the existence of an occupation layer also in this area. Two radiocarbon samples were analyzed, yielding mixed results: $15,250 \pm 70$ and $28,050 \pm 250 \mathrm{BP}$. The authors associate the more recent date with the cave paintings, not relying on the older one by the inconsistency with its stratigraphic position and with the rest of the series (Zhitenev et al. 2015).

Lately, U-Th dating of calcite flowstone underlying and overgrowing 22 of the paintings in three chambers of the cave was performed (Dublyansky et al. 2016, 2018a). The aim was to constrain the age of the artworks using an independent method. The results showed a period of calcite deposition that lasted until ca. $36.4 \mathrm{ky} \mathrm{cal} \mathrm{BP}$ and a second period that started at ca. $14.5 \mathrm{ky}$ cal BP. The authors link the ca. $22 \mathrm{ky}$-long hiatus to conditions of sub-zero temperatures inside the cave, which would impede the 
waterflow on the walls, hence the calcite deposition (Dublyansky et al. 2018a). The paintings overlie the oldest calcite and are covered by the most recent one; thus, they were made during the 36.4-14.5 ky cal BP timespan, under the extreme conditions of regional permafrost and sub-zero temperatures.

The repeated pattern of radiocarbon determinations for the different occupation areas inside the cave led us to suggest a timespan of ca. 19.6-16 ky cal BP (Fig. 2). We must remember that the lower layer at the Dome's Chamber remains undated, which could add a new Palaeolithic occupation period to Kapova. The links between the excavations and the paintings and the chronological constraints provided by the U-series analyses endorse the accuracy of this hypothesis. Thus, the Kapova graphic assemblage was created at the end of the Last Glacial Maximum (LGM), corresponding to the local Urals Upper Palaeolithic culture, when extreme cold and dry conditions pertained at the site.

\section{Methods}

Our study of Kapova cave involved several procedures. First, for mapping the cave and geolocating the decorated panels and areas, a Leica DistoX310 device and TopoDroid software were used. TopoDroid is an open source application that connects the Disto to an Android device via wireless Bluetooth connection (Trimmis 2018), allowing processing and recording the measurements in the site. Second, to observe the graphic

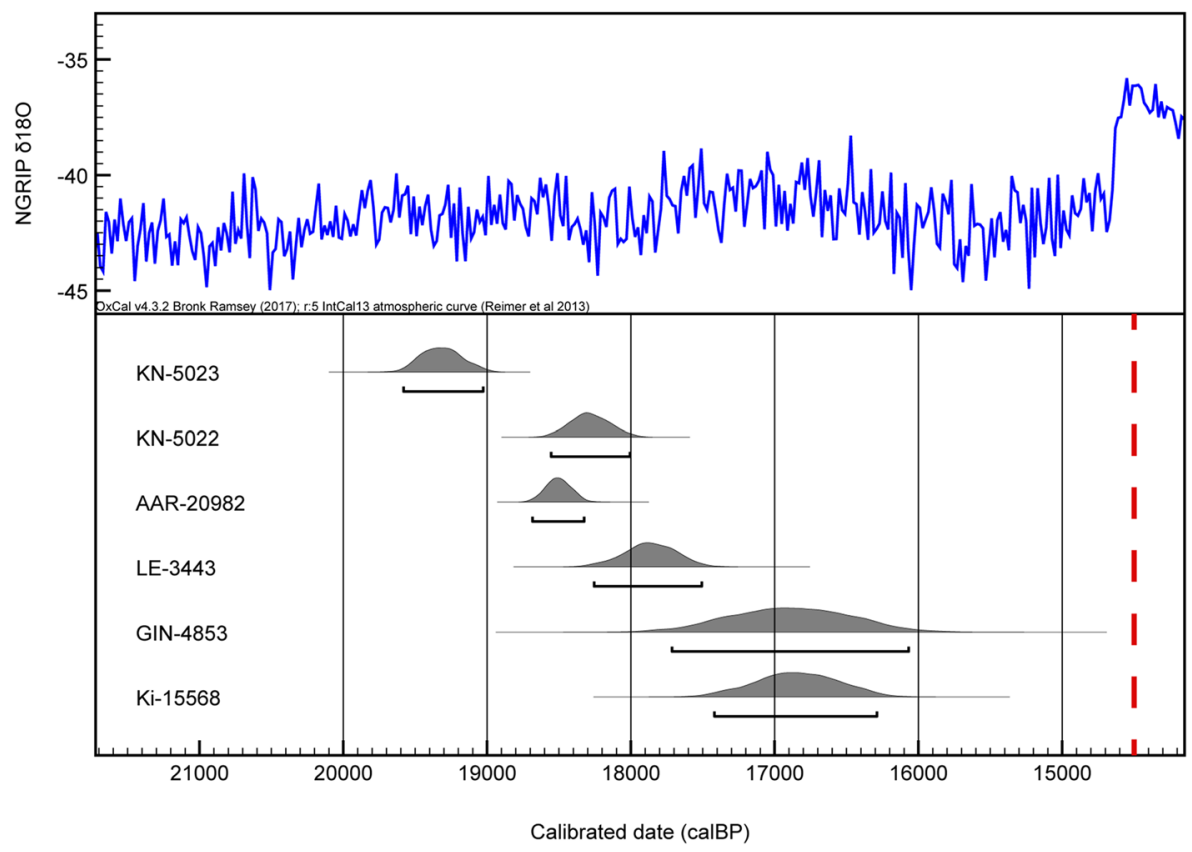

Fig. 2 Calibrated 14C determinations for the Kapova cave archaeological context, excluding results with large standard errors (>300 years). Dates have been calibrated with OxCal 4.3 (Bronk Ramsey 2017), using the IntCal13 dataset (Reimer et al. 2013). In the red dashed line, the older minimum date from U-series analyses (Dublyansky et al. 2016, 2018a). Sources: KN-5022, KN-5023, GIN-4853, LE-3443 (Shchelinsky and Sirokov 1999); Ki-15568 (Kotov 2014); AAR-20982 (Zhitenev et al. 2015) 
units ('GU'; this term comprises non-figurative marks, signs and representations), we have used three types of illumination with different luminosity and color temperature. We also used a handheld microscope $(\times 60-\times 120)$ to identify superimpositions and small remains of pigment. Photographs of the paintings were captured with a Sony® A6000 camera with a Sony FE 28-70 mm f/3.5-5.6 OSS lens and a Sony HVL-F60M remote flash. Color control and correction on the photos were made using a Colorchecker ${ }^{\circledR}$ Passport Photo chart and the Colorchecker ${ }^{\circledR}$ Camera Calibration software. The images were enhanced with the Dstretch ${ }^{\circledR}$ plug-in for the Image ${ }^{\circledR}$ software, and the digital tracings were made with Adobe Photoshop ${ }^{\circledR}$ and Adobe Illustrator ${ }^{\circledR}$. The photogrammetric models were created with Agisoft PhotoScan ${ }^{\circledR}$ Pro. The tracings of the paintings were created with the infographic methodology for recording parietal art (Fritz and Tosello 2007), adapted to 3D digital recording in the cases where photogrammetric models were used as a base (Fritz et al. 2016; Rivero et al. 2019; Salazar et al. 2019). Finally, all the data were registered in a database (Filemaker ${ }^{\circledR} 12$ ) and the statistical analyses were conducted using SPSS $®$ and PAST® software.

\section{Results}

\section{Art in Its Natural Context: the Decorated Spaces}

Kapova has four decorated chambers and an isolated non-figurative painting in a deadend passage. They are distributed in two levels of the cave (intermediate and upper), separated by $40-\mathrm{m}$ drop through the so-called Cascade Gallery (Fig. 3). The intermediate level is naturally divided into 3 large chambers (from the entrance to the end): Dome Chamber (DM), the Chamber of Signs (CS) and the Chamber of Chaos (CC), all of them profusely decorated. In the upper level, we have only documented GU in the Chamber of Paintings (CP) and an isolated motif in the so-called Western Dead-end (WD). The survey of the walls is not finished in all the lateral passages and galleries of the deepest area of the upper level (after the Chamber of Paintings), so other decorated areas could be found in the future. Considering the architecture of the cave and the well-defined gaps between decorated areas, we have structured the graphic assemblage in different 'panels'. We have created a comprehensive nomenclature for each of them, comprising the acronym of the panel, followed by the position from the entrance (' $R$ ' for right wall, ' $\mathrm{L}$ ' for left wall and ' $\mathrm{B}$ ' for boulder) and consecutive numeration for each chamber, also from the entrance of the cave to the end. Within a panel, we have assigned the number of each GU from the entrance to the end. For instance, the figure CC.R5.05 (a representation of a horse) is located in the Chamber of Chaos, on the fifth panel on the right wall, being the fifth figure starting from the right of the panel. This way, the name of each motif itself contains detailed information about its location within the cave. The final inventory shows 9 panels in the Dome Chamber ( 3 on the right, 3 on the left and 3 on boulders), 8 in the Chamber of Signs (one on the right and 7 on the left wall), 10 in the Chamber of Chaos ( 9 on the right and one on the left), two in the Chamber of Paintings (both in the left side) and a single one in the Western Deadend, on its left-hand side. 


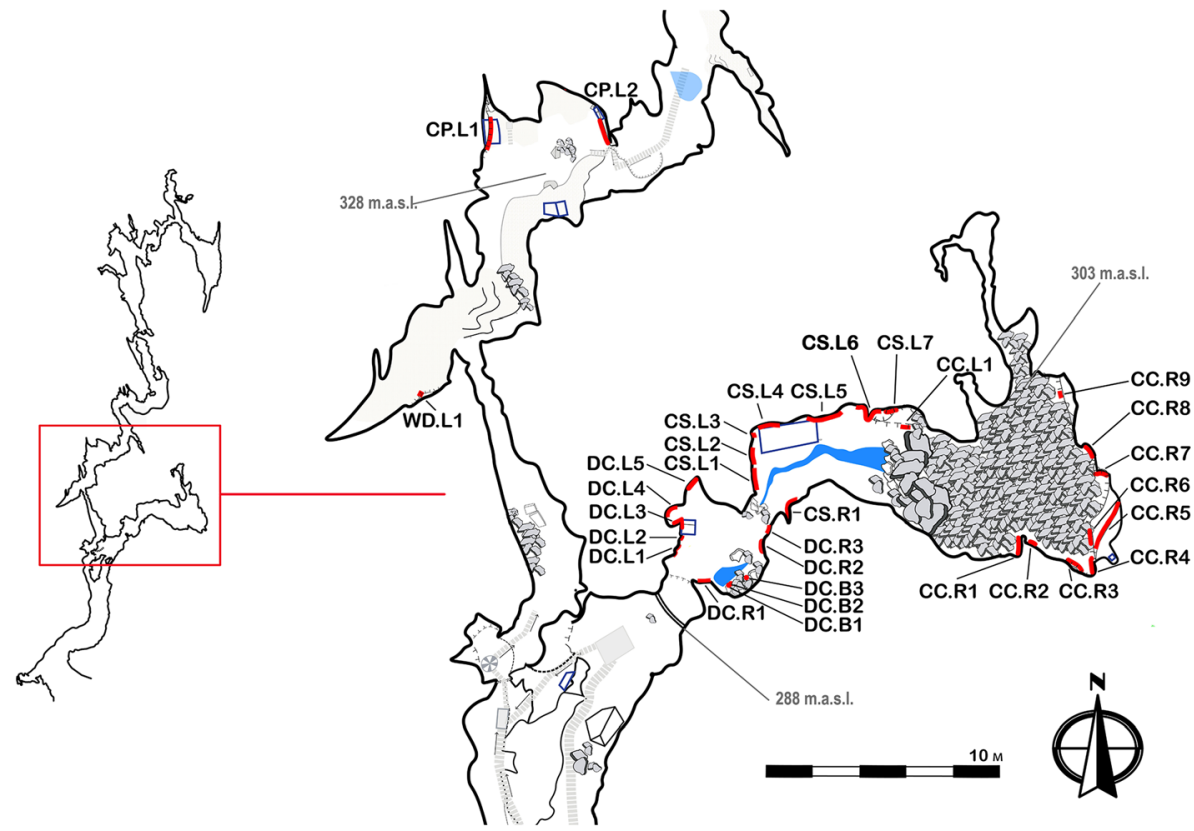

Fig. 3 Plan of the cave with the location of different panels (in red)

\section{Iconography}

We consider it necessary to discuss briefly the current state of preservation of the walls and the paintings prior to presenting the results of the analyses. Kapova is in an extremely active karst. Most of the cave walls are covered by thick layers of calcite including, naturally, the decorated panels. This should be taken into consideration for a proper reading of the results presented here. The total amount of GU is actually a minimum number, as some - or many - paintings may be covered by the calcite. The number of figurative representations and conventional symbols might also be minimal: some of them could be taken as 'simple non-figurative motifs' (hereafter 'SNFM') due to these preservation issues, which would result in an underestimation of their number. On the other hand, the amount of the latter might be overestimated for the same reason. We have decided to be prudent, reserving the categories of figurative representations (anthropomorphic and zoomorphic) and conventional symbols for certain images, defining the others as SNFM, even when some evidence indicated that a GU could belong to one of the former categories. Modern graffiti are common on the cave walls. Most of them there are alphabetic black paintings, and some are poor forgeries of zoomorphic figures easily recognizable as modern, one of them even dated to the twentieth century by C14-AMS (Dublyansky et al. 2018b).

These criteria led us to define $246 \mathrm{GU}$ in the site (Table 1). Among them, the majority are SNFM: a total of 162 . This category includes color patches, lines, dots and other simple motifs. The second category in number of instances (58) is 'conventional signs'. This comprises more structured motifs than the SNFM that appear repeated several times in the cave and/or in other Palaeolithic cave sites. They have a relevant role in Kapova's graphic assemblage, and several among them are very specific from 
Table 1 Inventory of the graphic entities in the different panels of Kapova

\begin{tabular}{|c|c|c|c|c|c|}
\hline Panel & Anthropo. & Conv. signs & NFSM & Zoomorphs & Total \\
\hline DC.R1 & - & - & 6 & - & 6 \\
\hline DC.R2 & - & 1 & 1 & - & 2 \\
\hline DC.R3 & - & 6 & 3 & - & 9 \\
\hline DC.L1 & - & - & 5 & - & 5 \\
\hline DC.L2 & - & 1 & 20 & - & 21 \\
\hline DC.L3 & - & 1 & 4 & - & 5 \\
\hline DC.B1 & - & - & 1 & - & 1 \\
\hline DC.B2 & - & - & 2 & - & 2 \\
\hline DC.B3 & - & 1 & - & - & 1 \\
\hline CS.R1 & - & - & 6 & - & 6 \\
\hline CS.L1 & - & 4 & 4 & 1 & 9 \\
\hline CS.L2 & - & 3 & 5 & - & 8 \\
\hline CS.L3 & - & 1 & 8 & - & 9 \\
\hline CS.L4 & - & 3 & 4 & - & 7 \\
\hline CS.L5 & - & 5 & 28 & - & 33 \\
\hline CS.L6 & - & 4 & 9 & - & 13 \\
\hline CS.L7 & - & 1 & 4 & - & 5 \\
\hline CC.R1 & 1 & 4 & 4 & 3 & 12 \\
\hline CC.R2 & - & - & 2 & - & 2 \\
\hline CC.R3 & - & - & 3 & - & 3 \\
\hline CC.R4 & - & 1 & 3 & - & 4 \\
\hline CC.R5 & 1 & 14 & 25 & 1 & 41 \\
\hline CC.R6 & 1 & - & - & 1 & 2 \\
\hline CC.R7 & - & 1 & 3 & - & 4 \\
\hline CC.R8 & - & - & 1 & - & 1 \\
\hline CC.R9 & - & 6 & 3 & - & 9 \\
\hline CC.L1 & - & - & 3 & - & 3 \\
\hline CP.L1 & 1 & - & 1 & 5 & 7 \\
\hline CP.L2 & 1 & 1 & 3 & 10 & 15 \\
\hline WD.L1 & - & - & 1 & - & 1 \\
\hline Total & 5 & 58 & 162 & 21 & 246 \\
\hline
\end{tabular}

this site, having no known equivalents in Western Europe (see below for a detailed discussion). The zoomorphic - animal - and anthropomorphic figures complete the parietal record, with 21 and 5 instances respectively.

Animal figures are without any doubt the most representative elements of UP cave art in our societies' collective mind. They represent the majority of the GU identified in several sites, especially during some periods (Ruiz-Redondo 2014, 2016). Nevertheless, their presence is variable, being absent or a real minority in other sites (for a compilation, see González Sainz 2004). This is the case for Kapova: with 21 zoomorphic figures, they only represent $8 \%$ of the corpus (Fig. 4). Conventional signs and, 


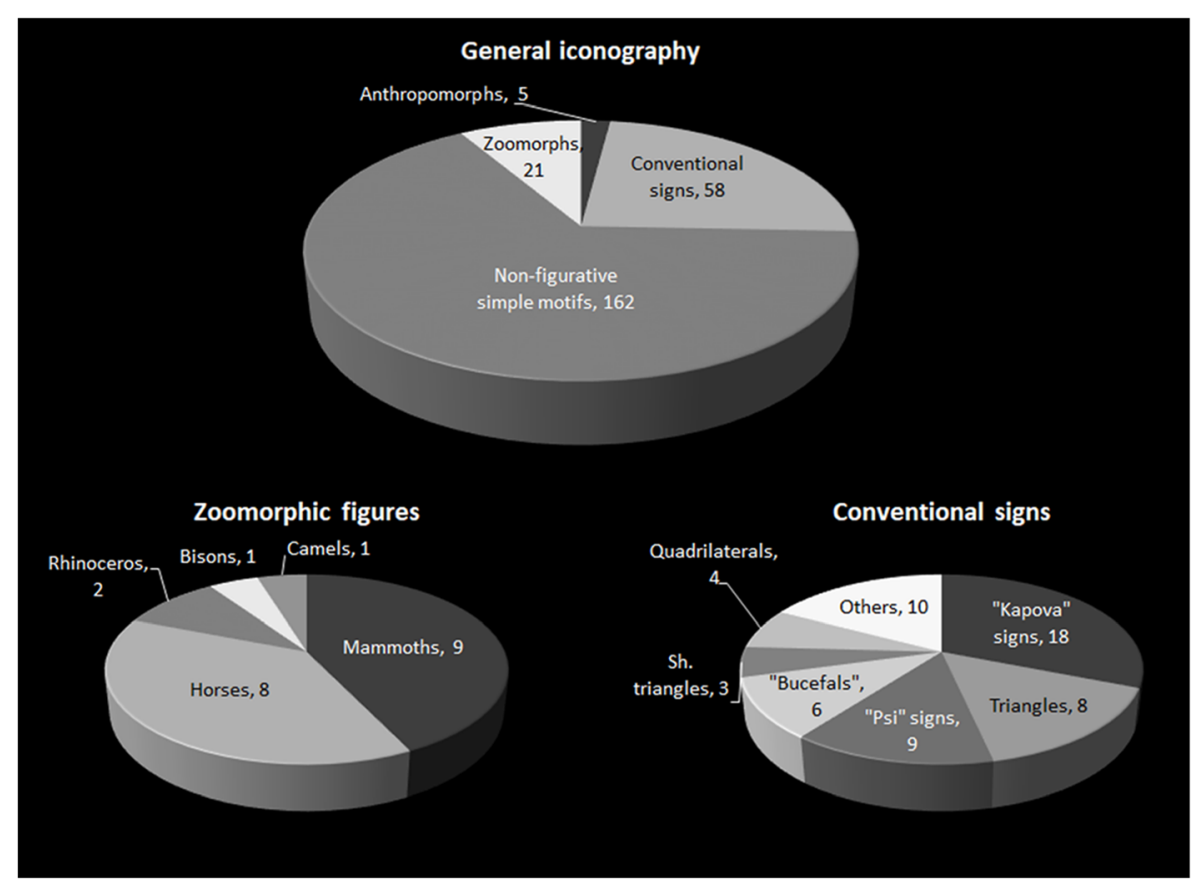

Fig. 4 Iconography of Kapova cave

especially, SNFM clearly outnumber the figurative representations, even considering the abovementioned issues of preservation that could lead to an underestimation of the latter. Among the species represented, the variability is low. Mammoths (9) and horses (8) represent $81 \%$ of the animal figures. Two rhinoceros, one bison and one camel complete the 'bestiary' of the site. All these species were present in the area at the time the Kapova paintings were made, with the camel being restricted to the Southern Urals within the European territory (Kosintsev 2007).

This catalogue diverges from the previous ones (Bader 1965; Ščelinskij and Širokov 1999; Lyakhnitsky et al. 2013; Zhitenev 2016; Shirokov 2018). The first variation is the camel, which does not appear in the oldest publications, as it was discovered in 2017 after perforating a calcite layer that covered it (Devlet et al. 2018). We have also identified two unpublished figures of horses (CS.L1.03 and CC.R5.05). Another horse (CP.L1.01) was known since the discovery of the cave paintings, but was probably taken to be a forgery and hence systematically ignored. The reason for rejection is probably that it is the only figure painted in black and it appears slightly deformed. One of us expressed previously his doubts about disregarding this representation (Zhitenev 2016). Indeed, the figure shows conventions present in other horses of Kapova (e.g. the shape of the head, the animation of the legs) (Fig. 5a). These are difficult to assume as part of a forgery when there is photographic evidence that this representation existed at the moment of the discovery of the others (1959), in a time when no UP cave art was found outside Franco-Cantabrian province. Who in the Southern Urals at that time could have had the knowledge on how to reproduce the UP techniques and conventions? Also new is the documentation of a second rhinoceros (CP.L2.06). It was previously claimed to be a mammoth (Bader 1965; Ščelinskij and Širokov 1999; 


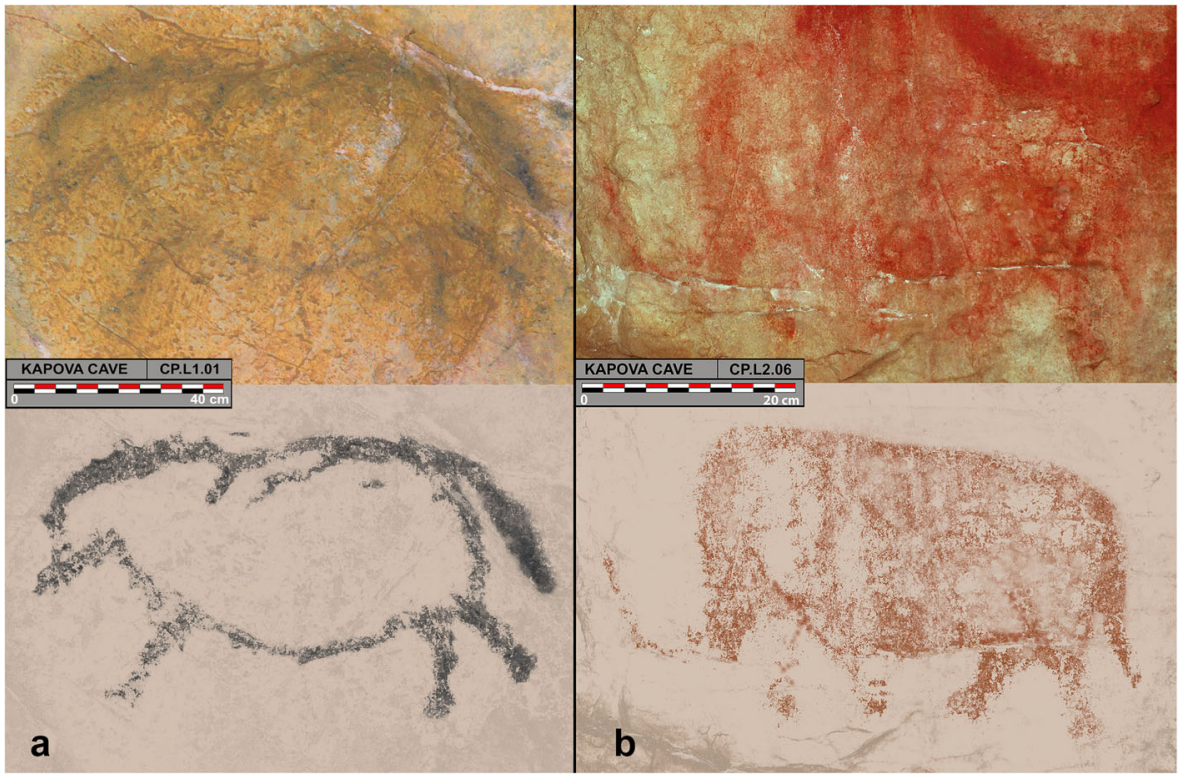

Fig. 5 a Graphic unit CP.L1.01, a horse representation previously taken as a forgery. The animation of the legs, conventional line in the neck and the shape of the head match with other horse figures of the cave. Up, photo enhanced using Dstretch plugin (YBK filter). Down, tracing of the image. b Graphic unit CP.L2.06, a rhinoceros representation previously interpreted as a mammoth. Up, photo enhanced using Dstretch plugin (YRE filter). Down, tracing of the image

Lyakhnitsky et al. 2013; Shirokov 2018). Recently, some doubts were expressed, identifying it as a 'mammoth or rhinoceros' (Zhitenev 2016). Thus, we applied colorimetric treatment and D-stretch enhancement, which clearly shows a rhinoceros representation (Fig. 5b). Finally, our inventory presents larger differences with Lyakhnitsky et al.'s catalogue. These authors identified a larger corpus of animal representations, including several new mammoths, an ibex, a 'buffalo' and even a 'dragon' (Lyakhnitsky et al. 2013). Most of them cannot be argued to be anything else than color patches or remains from indeterminable figures or signs; hence, we decided to do not include them.

The remaining figurative elements are the anthropomorphic (i.e. 'human') representations (Fig. 6). We have inventoried up to five possible human figures, although some of them are tentative identifications. Despite all of them fitting the criteria for identification of human body depictions (Fuentes 2013), their style and schematic design (different from other UP human figures and more reminiscent of Late Prehistory parietal art) call for caution. The anthropomorphs CP.L1.04 and CP.L2.13 (Fig. 6; ab) have been interpreted before (Shirokov 2018). CC.R1.09 and CC.R5.08 (Fig. 6; c-d) are new discoveries. In both cases, the vertical position of the body and the shape of the legs (slightly bent knees and feet in $90^{\circ}$ position from the legs) assure us that they cannot be another animal. CC.R6.02 (Fig. 6; e) has been identified as an anthropomorphic representation since its discovery (Bader 1965), but it has since been extensively argued that it shows human-animal mixed characteristics (Zhitenev 2015), being defined as a zoo-anthropomorph. This is essentially based on the existence of a tail, its stooping position and the shape of the head. Despite all these features being present, 

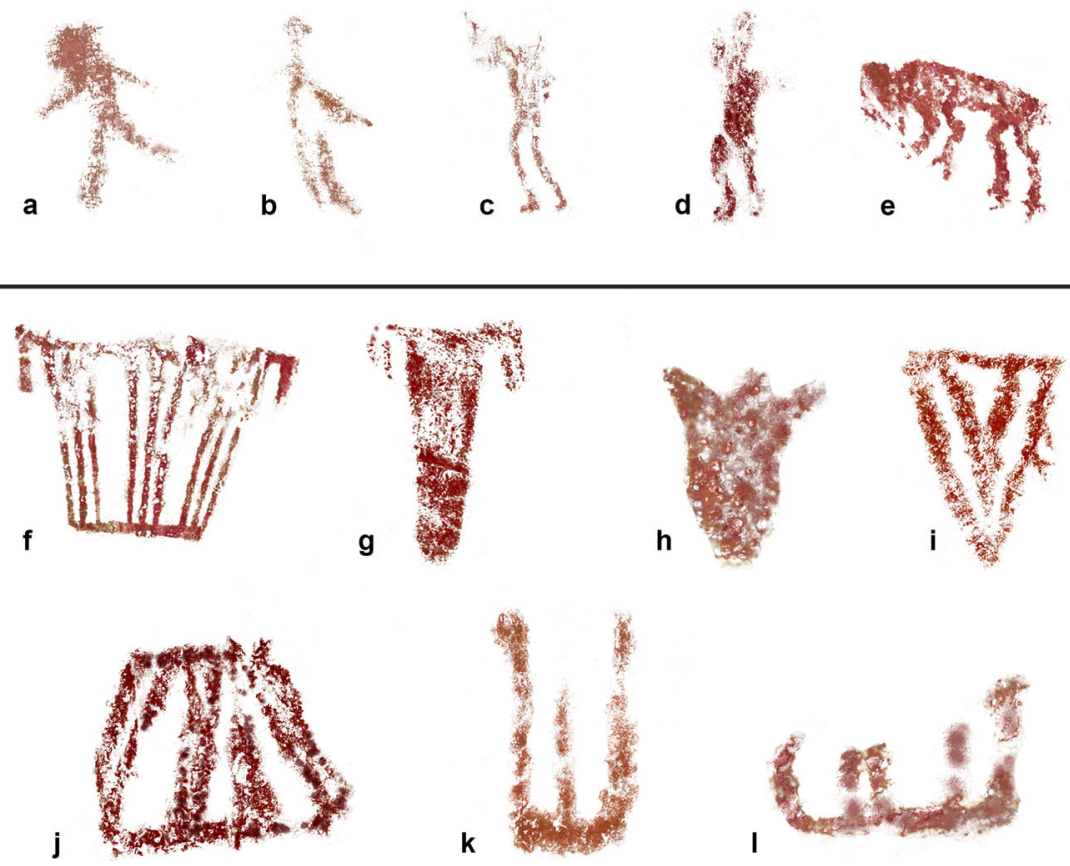

Fig. 6 Anthropomorphic representations (a-e) and most common types of conventional signs (f-l) at Kapova cave: f 'Kapova trapezoid'; $\mathbf{g}$ 'bucefal'; $\mathbf{h}$ 'shouldered triangle'; $\mathbf{i}$ 'triangle'; $\mathbf{j}$ 'quadrilateral'; $\mathbf{k}$ 'psi sign' and $\mathbf{l}$ 'comb-shaped sign'

it can be argued that (1) the 'tail' is just a color patch — and not well defined-(2) the shape of the head, in its current state of preservation, shows nothing diagnostically animal except maybe the size (slightly larger than life size) and (3) the position of the body is perfectly common among humans. Hence, considering the impossibility of proving its exceptional mixed character, we have preferred to take the conservative hypothesis and consider it 'just' a human representation.

The conventional signs are the most common (58) identifiable motifs in Kapova. They reach $24 \%$ of the total of GU, increased to $69 \%$ if we leave aside the SNFM (Fig. 3). At least six types are repeated several times in different parts of the cave. We have defined those as 'Kapova trapezoids' (a.k.a. 'eared trapezoids' in other publications), 'bucefals' (i.e. 'bovid heads'), 'shouldered triangles', 'triangles', 'quadrilaterals' and 'psi signs' (Fig. 6; f-1). Up to 18 'Kapova trapezoids' can be found distributed for every decorated area of the site, except the Dome Chamber. They are all inverted trapezoids with two L-shaped bulges in both sides of the upper part. They would be totally standardized, if it were not for the filling, where they show different patterns. 'Bucefals' and 'psi signs' are also quite standardized, while 'quadrilaterals' are a more 'open category'. We have divided the triangles as they show two different morphologies: some are 'shouldered' and with slightly concave sides, and the others are regular ones. Finally, up to 10 symbols appear just once in the parietal assemblage, including ovals, arrows and non-regular geometric signs. 


\section{Some Notes About the Spatial Distribution}

The spatial distribution of Palaeolithic artworks inside a cave has long been analyzed from different perspectives. From elemental pioneer studies (Leroi-Gourhan 1965; Vialou 1986) and the identification of different uses of the space (Lorblanchet 1995), to more detailed and complex analyses (González García 2001; Chippindale and Nash 2004; Ruiz-Redondo 2014) and the use of modern technologies (Jouteau et al. 2019), different authors have explored the issue of the location of GU and rock art panels within sites. It is not the aim of this paper to present a detailed analysis about the spatial distribution and the compositions, but a few insights and key facts about how Palaeolithic artists organized the parietal assemblage at Kapova cave.

The animal and human representations show a restricted distribution: they appear solely in six panels from the 30 that we defined for the cave. Furthermore, three major panels (CC.R1, CP.L1 and CP.L2) concentrate all the figurative representations except three horses and two anthropomorphs. The Chamber of Paintings concentrates almost $75 \%$ of the zoomorphic figures (15 of 21). This upper level shows also the highest variety of species: mammoths, rhinoceros and bison are exclusively from this area. The intermediate level concentrates the majority of the paintings but not a high number of figurative representations: two horses and a camel in a panel, and three other horses in three different panels. The situation is the opposite in the case of the conventional signs. They are all in the intermediate level, with the only exception being a big 'Kapova trapezoid' painted in the middle of the most complex animal composition of the site: CP.L2 (Fig. 7a). Thus, the chambers of the intermediate level not only concentrate 57 of 58 the conventional signs but also 157 of 162 SNFM. It is also noteworthy that in the intermediate level, the paintings are distributed from the entrance (Dome Chamber) to the very end (Chamber of Chaos), in 27 concentrations (panels) all along the gallery, while the upper level shows decoration in a highly restricted area (two panels of a single chamber).

This differential use of the space led to the conclusion that the Palaeolithic groups that inhabited Kapova conceived the cave as - at least - two different symbolic areas: one on the intermediate level and another on the upper level. The question that arises is as follows: were both painted by the same group/s? To answer this, it is necessary to analyze the associations in the compositions and the graphic conventions of the figures. This will yield further evidence about the link between both symbolic areas. In the case of observing similar behavior in terms of 'style' and the associations, we could probably conclude that both 'symbolic areas' were created by the same or closely related groups (Conkey and Hastorf 1990), and the differences in the iconography and organization of the space are probably due to a voluntary choice.

\section{Associations and Compositions}

As previously exposed, there is a clear dissymmetry in the distribution of the different types of motifs, especially evident in the comparison of their organization between both decorated levels. Despite this, can we find some patterns on the links between motifs? We have identified some, but prior to describing them, we present a note about the size of the sample. The number of figurative motifs in Kapova is low: 21 zoomorphic and 5 (probable) anthropomorphic figures. Therefore, we do not reach the minimum number 


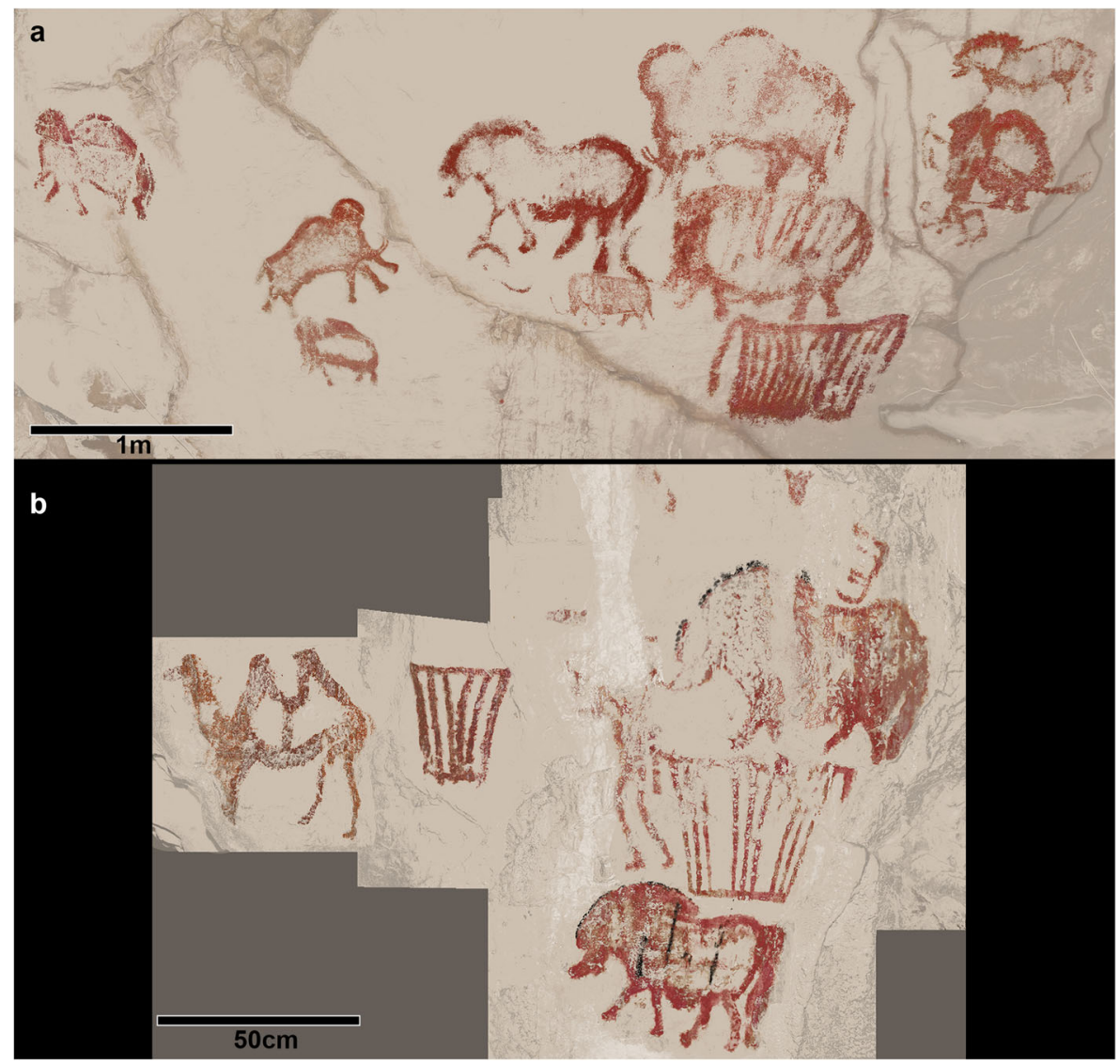

Fig. 7 a Panel CP.L2, comprising six mammoths, two horses, two rhinoceros, an anthropomorphic figure and a 'Kapova trapezoid'. b Panel CC.R1 with the representations of two horses, one camel, an anthropomorphic figure and several signs. Despite the differences in the iconography, the similarities are also remarkable: the morphology and the animation of the horses and the presence of a large 'Kapova trapezoid' in both compositions point to a shared — or closely related—symbolic culture of the authors

of 30 instances considered as the threshold for a statistical analysis to be completely reliable. In any case, we will present the results of some significance tests ( $Z$-scores) in order to illustrate and quantify our observations, being aware that their reliability is not optimal for Kapova.

The first pattern is the human-animal association. All the anthropomorphic figures are located in panels where there are zoomorphic representations. On the other hand, 20 out of 21 of the latter (quadruple the number of the former) share a panel with an anthropomorphic representation. The $Z$-scores yield a probability of $99.9 \%$ that this association is not random (i.e. due to quantitative fluctuations of the sample). This implies that the author/s of the paintings wished to link the human and animal representations in the same compositions. Another common association is the one between animal/human representations and a 'Kapova trapezoid'. In the panels with figurative representations, one or several of these signs can often be found (Fig. 7). Thus, 16 zoomorphic figures share panel with one or several of those signs. The $Z$ - 
scores show a weaker link between these two types, with a probability of $93.8 \%$. Despite the statistic being not that significant, it is noteworthy that one of those signs is the only one traced in the walls of the upper level, a space clearly reserved by the Palaeolithic individuals for figurative representations. These common patterns in both levels (sanctuaries?) nuance the contrasts observed in the iconographic distribution.

\section{A Matter of Style: Some Graphic and Technique Conventions}

The variability of the techniques used in Kapova cave is quite low. No Palaeolithic engraving has been found so far. Recently, the existence of finger flutings ('macaroni') has been reported in the Throat, at the entrance of the Dome chamber (Solodeinikov 2019), but a simple naked-eye examination makes it possible to rule out a UP (or even a prehistoric) chronology: they show no patina and preserve several burrs of clay. The vast majority of the paintings are made in red color, with diluted pigment in the cases where a determination is possible. There are four exceptions, all of them figurative and representing the same species: three bichrome horses and a completely black one (Fig. 8). For the former, the 'polychromes' consist of black lines outlining the mane area. Additionally, one of them also presents black vertical and subparallel lines in its body (CC.R1.08), and the other, lines outlining the rear legs (CC.R6.01). The geochemical pigment analysis revealed that these black paintings were made using charcoal (Pakhunov and Zhitenev 2015).

We will also highlight some visible patterns in the graphic conventions of the figurative representations. First, the laterality of the figures is essentially leftward. Just
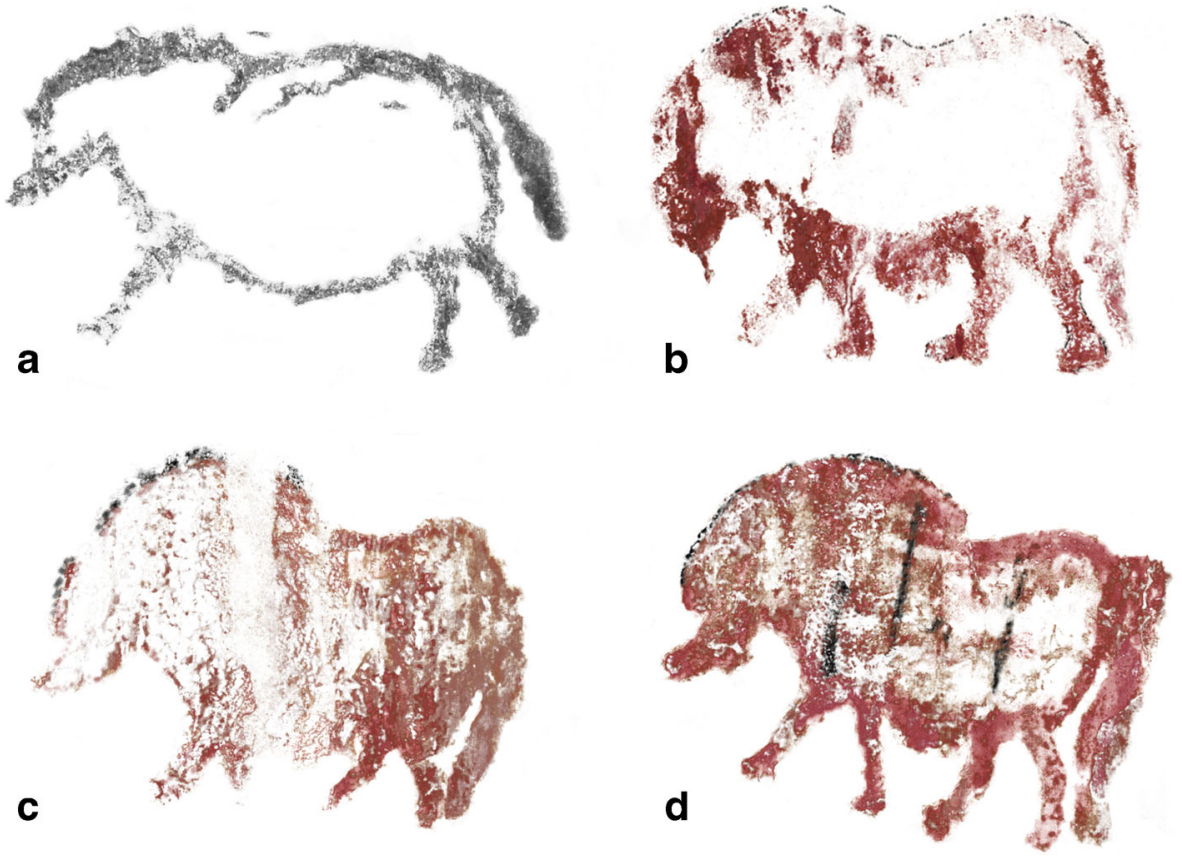

Fig. 8 Black and bichrome horse representations. a CP.L1.01. b CC.R6.01. c CC.R1.05. d CC.R1.08. The scale of each figure has been standardized for a better comparison 
one mammoth is facing towards the right, in the composition of panel CP.L2 (Fig. 7a). A direct link seems to exist between the laterality of the heads of animals and the handedness of the author. It consists of a statistically significant preference in orientating the heads leftward for the right-handed and rightward for the left-handed (Viggiano and Vannucci 2002). It has been claimed that the handedness frequency of UP societies was similar to that of current ones (Faurie and Raymond 2004), nearly 90/ 10 split between right-handed and left-handed. Thus, the data from Kapova cave could seem not striking. Nevertheless, studies about the laterality of the UP cave art show that the higher proportion of leftward animal representations may vary, depending on the species. Thus, while the majority of the species taken individually are oriented towards the left, the horse figures are the exception, being systematically drawn rightward (Sauvet 2005, 2019), especially in some periods and regions (Ruiz-Redondo 2016). In the case of Kapova, where the horse is the second most-represented species and the only ubiquitous one in both levels, this pattern is absent. Despite these data not being statistically significant due to the size of the assemblage, it is noteworthy.

Second, the animation in Kapova plays an important role in the graphic assemblage. Just one horse, one mammoth and a human figure do not express any kind of movement. All of them are located in the right side of the panel CP.L2 (Fig. 7a). The other representations are very dynamic, most of them showing the most complex type of animation: the 'coordinated' one (Leroi-Gourhan 1982) or even the 'complex coordinated' one (Azéma 1992). Most of the animals are depicted walking (or maybe trotting in the case of some horses), but there are a couple of interesting exceptions in the major composition of the panel CP.L2 (Fig. 7a). The mammoth CP.L2.02 is depicted in an aggressive attitude (Zhitenev 2018), showing all the conventions of charging (Azéma 2010: 297). Two facts could give us a clue for interpreting this unusual animation. First, it is the only figure in the panel (and in the cave) that is oriented rightwards. Second, under its legs, there is a second mammoth: smaller, without tusks and with a more straight-backed profile, which could represent a young individual. Combining these data, it can be suggested that we are looking at a scene of a mother protecting its calf, as has been argued for a couple of mammoths from La Baume Latrone (op. cit.: 298). Finally, both rhinoceros in the same panel also seem to be charging, considering the movement of their legs and the low position of their heads, with the horn projected forward.

The graphic conventions for the figurative representations are internally coherent within each species. The anthropomorphs are characterized by their simplicity: they are formed by contoured by simple lines, with no three-dimensional indication and lack of detail; not even the gender is identifiable. Mammoths are well-proportioned, simple but realistic, with thick feet and the trunk and the tail always drawn. Additionally, the tusks are represented in half of them. Kapova's horses are characterized by an exaggerated mane area, long and thick tail, and an odd shape of the head (curved and elongated).

In short, the spatial distribution of the iconography and the compositions points to the existence of - at least - two different 'symbolic areas' in Kapova, corresponding to both decorated levels of the karstic system. This could be due to (1) a chronological discrepancy, (2) two different - but contemporary - groups created the cave art or (3) a conscious choice of the Palaeolithic individuals. The common patterns observed in the techniques, and especially, in the graphic conventions, lead us to privilege the third hypothesis. Therefore, the human group/s that created Kapova's cave paintings 
intentionally divided the site into two symbolic spaces, with different cultural significances and, possibly, distinct roles in their society.

\section{Kapova Cave in the Context of European Palaeolithic Symbolism}

Stylistic analysis has always been central for archaeological interpretation and can serve to develop different kinds of hypotheses (Conkey and Hastorf 1990). It has been widely disputed in Palaeolithic Art studies, owing to a traditional overconfidence on the reliability of its conclusions (Lorblanchet and Bahn 1993), especially for the inherent subjectivity of style-based chronologies (Lorblanchet 1994). Despite this, drawing analogies between sites from the same chronology may serve to disclose cultural links between human groups (e.g. Sieveking 2003; Fortea Pérez et al. 2004; Ruiz-Redondo 2016). Finding the place of Kapova cave within UP cultural dynamics is especially interesting, due to its 'isolated' geographic location within the distribution of Palaeolithic decorated caves.

In terms of iconography, the distribution of species represented in Kapova is quite original. It is noteworthy that all the fauna depicted in Kapova was present during MIS2 in the Southern Urals, including the camel. Nevertheless, the youngest remains of Camelus ferus found in Southern Urals come from the Middle Valdai (ca. 35-24 ky cal BP), older than the supposed chronology of Kapova's paintings (Kosintsev 2007). Thus, the iconography itself does not link the site with other decorated caves in Europe but shows a strong local component. The most frequent animal is the mammoth, which is the situation in just one major UP sanctuary: Rouffignac (Barrière 1982; Plassard 1999). This cave art site is Magdalenian, but its supposed chronology is much more recent (ca. 3000-2000 years) than Kapova. The graphic assemblage of this French site is also exceptional for its period, despite mammoths also being present in low numbers in other sites from the Dordogne (Bernifal) and French Pyrenees (Trois Frères). Mammoth representations are more frequent (excluding Rouffignac) in Early Upper Palaeolithic sites, especially in the Rhone-Languedoc area (Sauvet and Wlodarczyk 2001). Nevertheless, stylistically, the mammoths from Kapova are similar neither to those from the French Magdalenian nor the ones from the Early Upper Palaeolithic. Their naturalism could evoke the former ones, but they lack the Magdalenian conventions, such as the depiction of the fur and the profusion of anatomic details (eyes, ears, etc.).

The second species in number of individuals is the horse. This offers not many clues for defining links with other sites, as it is the most represented species in Palaeolithic cave art and its presence is attested during the whole UP (Sauvet and Wlodarczyk 2001). Three representations are bichrome, a technique only documented in a few UP cave sites. Despite this, the 'bichromy' of Kapova's horses consists just of a black line to reinforce the mane area, which makes it risky to link them to the very complex representations from Western European sites, such as Altamira, Ekain, Lascaux or Font de Gaume. In these sites, the combination of colors is most likely used to create the impression of volume, instead of just partially outlining the figures.

Rhinoceros often appear together with mammoths in the same UP parietal sites, with normally the latter species being more numerous. This association is not striking, as they occupied similar ecological niches during the Palaeolithic. Once more, this iconography is more frequent in much older chronologies than the occupations in Kapova, with the exceptions of Rouffignac (Barrière 1982) and Les Trois Frères 
(Bégouën and Breuil 1958), the latter one with just one representation of each of those species. Kapova's rhinoceroses display a unique set of features. They have just one exceptionally large horn with a second short one barely outlined, their head is very short and in low position, and the body is massive with a quite straight-backed outline. They have no clear parallels with other UP rhinoceros representations in Europe. These are characterized by a long head with two horns, a sinuous back outline and the depiction of hair, especially under the head and on the belly. Kapova's rhinoceroses, like Western European ones, fit into the variability of Coelodonta antiquitatis (woolly rhinoceros). Hence, we have to assume that the differences are due to stylistic variants.

Two species have only been depicted once in Kapova walls. The single bison shows not many special stylistic features. Perhaps the most interesting is that it displays the horns in front view, which it has in common with the other two bison representations in Eastern Europe cave art: the ones from Coliboaia (Clottes et al. 2012) and Romualdova (Ruiz-Redondo et al. 2019). The second animal species is the recently discovered (Devlet et al. 2018) camel (Camelus ferus). Despite there being no other camels in Western Europe Palaeolithic art, we have identified another representation of this animal in the cave of Igniatievskaya (Southern Urals), previously interpreted as a human-animal mixed figure (Ščelinskij and Širokov 1999). They share some stylistic characteristics, despite the latter one being painted in black and poorly preserved. This singularity supports the idea of the existence of a shared symbolic culture between the human groups that decorated both sites, distant around $300 \mathrm{~km}$ (Fig. 1).

The number of potential human figures (5) does not seem striking, but that perception changes if we consider their specific role within the graphic assemblage: they represent almost $20 \%$ of the figurative motifs. The cave has one of the highest ratio of human-animal representations, after Grotta dell'Addaura in Italy (Bovio Marconi 1953) and Fronsac in France (Paillet et al. 2018), excluding sites with fewer than 20 figurative motifs. Beyond their high percentage, their particularity is also shown in their style, which is linear and schematic, closer in their aspect to post-Palaeolithic art human figures than to Palaeolithic ones. While it is proven that anthropomorphs in UP rock art are generally less naturalistic than zoomorphs, the figures from Kapova reach a higher level of schematism, being reduced to simple lines that, nevertheless, allow their identification as 'human figures'. Perhaps a closer analogy to them in the UP can be found in the anthropomorphic figure of the 'scène du puits' at Lascaux (Aujoulat 2004), whose limbs are also reduced to simple lines. We might also be tempted to link this relevant presence of the human figure to an inherited tradition from Russian Gravettian mobiliary art. This idea cannot be entirely disregarded, although, Kapova's human are schematic, dynamic and show no apparent gender, while Gravettian statuettes are more naturalistic, static and clearly feminine (Kozlowski 1992, Abramova 1995, Gvozdover 1995). Thus, we are not able to establish a link between both graphic traditions.

As mentioned above, a majority of the conventional signs in Kapova are very specific and, in most of the cases, exclusive to this site. There are no exact analogies for the 'Kapova trapezoids', 'psi signs' and 'bucefals', and the triangles are too simple to exclude a phenomenon of convergence to explain their ubiquity in Palaeolithic art. On the other hand, two 'lattice' signs evoke vividly the Herrerías-type parrilla signs (Jordá Cerdá and Mallo Viesca 1972) present in several sites, especially in northern Spain. The 'shouldered triangles' are slightly more specific: always inverted, with an appendix in the middle of the upper side, and both lateral sides are concave. A parallel 
of them could be found in two signs at Romualdova pećina (Croatia), also painted in red and associated with figurative images (Ruiz-Redondo et al. 2019). Considering that the chronology of the art at this site could be similar to the one for Kapova paintings, and including a certain reminiscence between the bisons at both caves, perhaps these analogies could be meaningful. In any case, the distance between these two sites and the lack of knowledge of the cave art in the territory in between encourage caution in drawing such conclusions.

\section{Conclusion}

We presented here the results of our first analysis of the iconography, techno-stylistic conventions and spatial distribution at Kapova cave. This site, at the edge of the distribution area of European Palaeolithic art and far away from other cave sanctuaries, is key to defining and understanding potential long-distance cultural networks during the UP. A number of the research based on its cave art had establishing a direct link between Kapova and Western Europe Palaeolithic art as a goal (e.g. Shirokov 2015; Zhitenev 2015). In this paper, we offered some data to contextualize this site within the UP social and cultural dynamics. All Kapova paintings share essential characteristics with their counterparts from SW Europe. The techniques, iconography, graphic conventions and organization inside the cave have clear reminiscences of the Palaeolithic art 'style', generally speaking. The employment of diluted red ocher (sometimes combined with dry charcoal), the use of natural reliefs for the compositions, the depiction of naturalistic animal figures and their grouping in specific panels are highly recognizable characteristics of UP graphic culture. Nevertheless, if we go beyond a qualitative first impression to conduct a deeper analysis, a large number of specificities emerge. The iconography is not similar to any UP cave site in Western Europe from the same period. In quantitative terms, the high percentage of mammoths and 'human' figures highlights the originality of the graphic assemblage. The presence of a camel and the unique geometric signs points to a strong influence of a local tradition in the symbolism of Kapova's painters. The graphic conventions are not typical from sites in other areas. Figurative images display a markedly original panoply of features. Maybe the closer parallel to this graphic assemblage could be found at Romualdova, in Croatia. They probably share chronology, a high importance of geometric signs and the presence of schematic 'human' figures, 'U-shaped' horn bison and 'shouldered triangles' (Ruiz-Redondo et al. 2019). Nevertheless, a strong case for a cultural relationship between both sites cannot be made, due to (1) the lack of evidence (other than the art itself) endorsing it, (2) the large distance that separates both sites and (3) the gap of UP cave art from that period in the area between them. At a smaller scale, schematic human figures and another camel can be found at the cave of Igniatievskaya, which reinforces the idea of a strong local component within these societies' symbolic culture. Hence, is Kapova cave art a reflection of a migration or fluid relationships between human groups from the Urals and Western Europe (as several authors have proposed in the past)? The data presented in this paper do not endorse that conclusion. While we do not suggest an independent origin for both graphic traditions, both human groupings do not share the same symbolic culture. Nevertheless, evidence of other human activities evokes a link with Western European caves, such as the making of deer tooth personal 
ornaments (rarely found in the Russian Plain). Thus, if we imagine a common origin and a dissemination, two scenarios can be drawn for the time when Kapova was created. First, this behavior was recently adopted from other groups by the individuals that painted the cave so they adapted to their own collective imagery. And second, the dissemination of this phenomenon took place a longer time before the depictions were made, following an independent evolutionary path that led to the original features shown by Kapova graphic assemblage. Further discoveries in the Urals and the territories between there and Central and Western Europe would provide a broader picture and shed new light on the cultural transmission and social networks of UP societies.

Acknowledgements We would like to thank Dr. W. Davies for the language edit. We are also deeply grateful to Y. Kuzminova for the help with the image recording, processing and the tracings and to D. Albov for the help with the topographic plan of the cave, and to all the students from the MSU that participated with great interest in the fieldwork. The authors are grateful to the editor and the anonymous reviewers for their helpful comments, which improved the final version of this manuscript. All remaining errors are ours.

Funding This research is part of the 'Southern Urals archaeological expedition', led by VZ and funded by the Lomonosov Moscow State University (MSU). AR-R has received financial support from the British Academy for leading the PALAEOARTEAST ('Defining cultural boundaries in the European Upper PALAEOlithic: Archaeology and Rock arT in EASTern Europe') project, within the framework of the Newton International Fellowship program (NIF\R1\180205).

\section{Compliance with Ethical Standards}

Conflict of Interest The authors declare that they have no conflict of interest.

Open Access This article is licensed under a Creative Commons Attribution 4.0 International License, which permits use, sharing, adaptation, distribution and reproduction in any medium or format, as long as you give appropriate credit to the original author(s) and the source, provide a link to the Creative Commons licence, and indicate if changes were made. The images or other third party material in this article are included in the article's Creative Commons licence, unless indicated otherwise in a credit line to the material. If material is not included in the article's Creative Commons licence and your intended use is not permitted by statutory regulation or exceeds the permitted use, you will need to obtain permission directly from the copyright holder. To view a copy of this licence, visit http://creativecommons.org/licenses/by/4.0/.

\section{References}

Abramova, Z. (1995). L'Art paléolithique d'Europe orientale et de Sibérie. Grenoble: Jérôme Millon.

Aubert, M., Brumm, A., Ramli, M., Sutikna, T., Saptomo, E. W., Hakim, B., Morwood, M. J., van den Bergh, G. D., Kinsley, L., \& Dosseto, A. (2014). Pleistocene cave art from Sulawesi, Indonesia. Nature, 514, 223-227.

Aubert, M., Setiawan, P., Oktaviana, A. A., Brumm, A., Sulistyarto, P. H., Saptomo, E. W., Istiawan, B., Ma'rifat, T. A., Wahyuono, V. N., Atmoko, F. T., Zhao, J.-X., Huntley, J., Taçon, P. S. C., Howard, D. L., \& Brand, H. E. A. (2018). Palaeolithic cave art in Borneo. Nature, 564, 254-257.

Aujoulat, N. (2004). Lascaux. Le geste, l'espace et le temps. Paris: Seuil.

Azéma, M. (1992). La représentation du mouvement dans l'art animalier paléolithique des Pyrénées. Bulletin de la Société Préhistorique Ariège-Pyrénées, 47, 19-76.

Azéma, M. (2010). L'art des cavernes en action. Tome 2. Paris: Errance.

Bader, O. N. (1965). Kapova cave. Moscow: Nauka (In Russian). 
Bahn, P., Pettitt, P. B., \& Ripoll, S. (2003). Discovery of Palaeolithic cave art in Britain. Antiquity, 77, 227231.

Barrière, C. (1982). L'art pariétal de Rouffignac. Paris: Picard, Fondation Singer-Polignac.

Bégouën, L., \& Breuil, H. (1958). Les Cavernes du Volp. Trois Frères - Tuc d'Audoubert à MontesquieuAvantès (Ariège). Paris: Travaux de l'Institut de Paléontologie Humaine.

Bovio Marconi, J. (1953). Incisioni rupestri all'Addaura (Palermo). Bullettino di Paletnologia Italiana, 8(5), $5-22$.

Cartailhac, E. (1902). La grotte d'Altamira, Espagne. "Mea culpa" d'un sceptique. L'Anthropologie, 13, 348354.

Chippindale, C., \& Nash, G. (2004). Pictures in place: the figured landscapes of rock-art. New York: Cambridge University Press.

Clottes, J., Besesek, M., Gély, B., Ghemis, C., Kenesz, M., Lascu, V. T., Meyssonnier, M., Philippe, M., Plichon, V., Prud'homme, F., Radu, V. A., Rus, T., \& Tociu, R. L. (2012). Découverte d'une nouvelle grotte ornée paléolithique en Roumanie, dans le département du Bihor. In J. Clottes (Ed.), L'art pléistocène dans le monde Actes du Congrès IFRAO, Tarascon-sur-Ariège, septembre 2010, Symposium «Art pléistocène en Europe». Préhistoire, Art et Sociétés-B.S.P.A, 65-66, 513-528.

Conkey, M. W., \& Hastorf, C. (Eds.). (1990). The uses of style in archaeology. Cambridge: Cambridge University Press.

David, B., Geneste, J.-M., Petchey, F., Delannoy, J.-J., Barker, B., \& Ecclestone, M. (2013). How old are Australia's pictographs? A review of rock art dating. Journal of Archaeological Science, 40(1), 3-10.

Devlet, E. G., Guillamet, E., Pakhunov, A. S., Grigoriev, N. N., \& Gainullin, D. A. (2018). Preliminary results of studies of the camel figure at the chamber of Chaos at Shulgan-Tash (Kapova) cave. Ural'skij Istoriceskij Vestnik, 58(1), 141-148 (In Russian).

Dublyansky, Y. V., Moseley, G. E., Spötl, C., Liakhnitsky, Y. S., Zhitenev, V. S., \& Edwards, R. L. (2016). Uranium-thorium dating of the Palaeolithic cave art in Shulgan-Tash (Kapova) cave. In International Scientific Symposium The problems of conservation, preservation of Palaeolithic paintings from the cave Shulgan-Tash and the development of tourism infrastructure at the sight «the land of Ural-Batyr» (pp. 55-58). Ufa: Ministry of Culture of Bashkortostan.

Dublyansky, Y. V., Moseley, G. E., Liakhnitsky, Y. S., Cheng, H., Edwards, R. L., Scholz, D., Koltai, G., \& Spötl, C. (2018a). Late Palaeolithic cave art and permafrost in the Southern Ural. Scientific Reports, 8, 12080.

Dublyansky, Y. V., Liakhnitsky, Y. S., \& Spötl, C. (2018b). Data on the 14C date obtained from the charcoal figure "black fox" in Shulgan-Tash (Kapova) cave, Southern Ural, Russia. Data in Brief, 21, 1101-1105.

Faurie, C., \& Raymond, M. (2004). Handedness frequency over more than ten thousand years. Proceedings of the Royal Society B, 271, S43-S45.

Fortea Pérez, J., Fritz, C., García, M., Sanchidrián Torti, J. L., Sauvet, G., \& Tosello, G. 2004. L'art pariétal paléolithique à l'épreuve du style et du carbone-14. In M. Otte (Ed.), La Spiritualité (pp. 163-175). Liège: ERAUL (106).

Fritz, C., \& Tosello, G. (2007). The hidden meaning of forms: methods of recording Paleolithic parietal art. Journal of Archaeological Method and Theory, 14(1), 48-80.

Fritz, C., Willis, M. D., \& Tosello, G. (2016). Reconstructing Palaeolithic cave art: the example of Marsoulas cave (France). Journal of Archaeological Science: Reports, 10, 910-916.

Fuentes, O. (2013). La forme humaine dans l'art magdalénien et ses enjeux. Approche des structures élémentaires de notre image et son incidence dans l'univers symbolique et social des groupes paléolithiques. $\mathrm{PhD}$ dissertation. Paris: Universitéde Paris I Panthéon-Sorbonne.

González García, R. (2001). Art et espace dans les grottes paléolithiques cantabriques. Grenoble: Jérôme Millon.

González Sainz, C. (2004). Arte parietal en la región Cantábrica: centros y peculiaridades regionales. In M. A. Fano (Ed.), Las sociedades del Paleolítico en la Región Cantábrica (Vol. 8, pp. 403-424). Bilbao: Anejos de Kobie.

Gvozdover, M. (1995). Art of the mammoth hunters: the finds from Avdeevo. Oxford: Oxbow Books.

Huyge, D., Aubert, M., Barnard, H., Claes, W., Darnell, J. C., De Dapper, M., Figari, E., Ikram, S., LebrunNélis, A., \& Therasse, I. (2007). Lascaux along the Nile: Late Pleistocene rock art in Egypt. Antiquity, 81(313), 1-6.

Jordá Cerdá, F., \& Mallo Viesca, M. (1972). Las Pinturas de la Cueva de las Herrerías, (Llanes, Asturias). Salamanca: Universidad de Salamanca.

Jouteau, A., Feruglio, V., Bourdier, C., Camus, H., Ferrier, C., Santos, F., \& Jaubert, J. (2019). Choosing rock art locations: geological parameters and social behaviours. The example of Cussac Cave (Dordogne, France). Journal of Archaeological Science, 105, 81-96. 
Kosintsev, P. (2007). Late Pleistocene large mammal faunas from the Urals. Quaternary International, 160, $112-120$.

Kotov, V. G. (2014). Studies of the multilayer Paleolithic settlement in the cave of Shulgan-Tash (Kapova). Transactions of the faculty of History of the Saint Petersburg State University, 18, 120-141 (In Russian).

Kozlowski, J. K. (1992). L'art de la Préhistoire en Europe Orientale. Paris: CNRS Éditions.

Kuhn, S. L., \& Stiner, M. C. (2019). Hearth and home in the Middle Pleistocene. Journal of Anthropological Research, 75(3), 305-327.

Leroi-Gourhan, L. (1965). Préhistoire de l'art occidental. Paris: Lucien Mazenod.

Leroi-Gourhan, A. (1982). The dawn of European art. An introduction to Palaeolithic cave painting. Cambridge: Cambridge University Press.

Lorblanchet, M. (1994). La datation de l'art paléolithique. Bulletin de la Société des Études Littéraires, Scientifiques et Artistiques du Lot, CXV(3), 161-182.

Lorblanchet, M. (1995). Les grottes ornées de la Préhistoire. Nouveaux regards. Éditions Errance, París.

Lorblanchet, M., \& Bahn, P. G. (Eds.). (1993). Rock art studies: the post-stylistic era or where do we go from here? Oxford: Oxbow Monographs in Archaeology.

Lyakhnitsky, Y., Minnikov, O., \& Yushko, A. (2013). Drawings and signs of Shulgantash (Kapova) cave. Catalogue of images. Ufa: Kitap.

Paillet, P., Paillet, E., Dandurand, G., Bonnet-Jacquement, P., Boudadi-Maligne, M., Costamagno, S., Langlais, M., Laroulandie, V., Lefebvre, A., \& Mallye, J.-B. (2018). La grotte de Fronsac à VieuxMareuil (Dordogne) : Un dispositif pariétal revisité ou les bénéfices d'une approche interdisciplinaire. Les Nouvelles de l'archéologie, 154, 25-32.

Pakhunov, A. S., \& Zhitenev, V. S. (2015). New data on upper Palaeolithic paint recipes: scientific examination of massive paint remains from Kapova cave, Southern Ural, Russia. Stratum plus, 1, 125136 (In Russian).

Petrin, V. T. (1997). Le Sanctuaire Paléolithique de la Grotte Ignatievskaia a l'Ural du Sud. Liège: ERAUL, 81.

Plassard, J. (1999). Rouffignac : le sanctuaire des mammouths. Paris: Seuil.

Rivero, O., Ruiz López, J. F., Intxaurbe, I., Salazar, S., \& Garate, D. (2019). On the limits of 3D capture: A new method to approach the photogrammetric recording of Palaeolithic thin incised engravings in Atxurra cave (northern Spain). Digital Applications in Archaeology and Cultural Heritage, 14, e00106.

Ruiz-Redondo, A. (2014). Entre el Cantábrico y los Pirineos: el conjunto de Altxerri en el contexto de la actividad gráfica magdaleniense. Santander: Nadir.

Ruiz-Redondo, A. (2016). Le comportement symbolique des derniers chasseurs cueilleurs paléolithiques : regard sur l'art rupestre du Magdalénien cantabrique. L'Anthropologie, 120(5), 568-587.

Ruiz-Redondo, A., Mihailovic, D., \& Kuhn, S. (2018). First results of rock art survey in Central Balkans: Analysis of the graphic remains of Selačka 3 (Serbia). In H. Floss, A. Pastoors, \& A. (Eds.), Palaeolithic rock and cave art in Central Europe? (pp. 151-159). Verlag Marie Leidorf: Rahden.

Ruiz-Redondo, A., Komso, D., Garate, D., Moro-Abadía, O., González-Morales, M.-R., Jaubert, J., \& Karavanic, I. (2019). Expanding the horizons of Palaeolithic rock art: The site of Romualdova Pećina (Croatia). Antiquity, 368, 297-312.

Salazar, S., Garate, D., Intxaurbe, I., Salazar, S., Rivero, O., \& Moreno, J. (2019). An unknown "classic cave": Re-evaluation of El Salitre (Ajanedo, Cantabria, Spain) rock art with 3D digital recording methodologies. Journal of Archaeological Science: Reports, 26, 101921.

Sanz de Sautuola, M. (1880). Breves apuntes sobre algunos objetos prehistóricos de la Provincia de Santander. Santander: imp. y lit. de Telesforo Martínez.

Sauvet, G. (2005). Latéralisation des figures animales dans les arts rupestres: un exemple de toposensitivité. Munibe, 57, 79-93.

Sauvet, G. (2019). La superior posición jerárquica del caballo en la iconografía parietal paleolítica. Nailos, 5, 43-64.

Sauvet, G., \& Wlodarczyk, A. (2001). L'Art Pariétal, miroir des sociétés paléolithiques. Zephyrus, 53-54, $217-240$.

Ščelinskij V.E., \& Širokov V.N. (1999). Höhlenmalerei im Ural. Kapova und Ignatievka. Die altsteinzeitliche Bilderhöhlen im südlichen Ural. Sigmaringen: Jan Thorbecke Verlag.

Shchelinsky, V. E. (1987). Some results on new researches in Shulgan-Tash (Kapova) cave in the Southern Urals. In Questions of ancient and Middle age's history of the Southern Urals (pp. 5-16). Ufa: USSR Academy of Sciences, Bashkirian branch, Institute of History, Language and Literature (In Russian).

Shchelinsky, V. E. (1990a). Parietal art of the Kapova cave in the Southern Urals (dates, location, cultural background). The problems of studying the rock art in USSR (pp. 47-55). Moscow: Nauka. (In Russian). 
Shchelinsky, V. E. (1990b). The research at the Kapova cave (to the methodology of studying primitive cave sanctuaries). The Brief Communications of Institute of Archaeology, 202, 89-94 (In Russian).

Shchelinsky, V. E. (1993). Kapova cave in the Southern Urals - a unique site of European Upper Paleolithic. In The problems of culture's genesis and cultural heritage. Part 2. Archaeology and study of cultural processes and phenomenon (pp. 23-34). Saint-Petersburg: The Institute for the History of Material Culture (IHMC) RAS. (In Russian).

Shchelinsky, V. E. (1997). Palaeographic environment and archeological complex of Upper Paleolithic cave sanctuary Shulgan-Tash (Kapova). In The cave Palaeolithic of the Urals: proceedings of the international conference (Ufa, 9-15 september 1997) (pp. 29-38). Ufa: Print (In Russian).

Shchelinsky, V. E. (2001). The parietal art of Upper Paleolithic sanctuary in Shulgan-Tash (Kapova) cave in the Southern Urals: the "horses and signs" composition in the chamber of chaos. In Problems of primitive culture (pp. 33-53). Gilem: Ufa (In Russian).

Shirokov, V. N. (2015). Some comparisons of the Paleolithic cave art between the Urals and Western Europe. In S. Sazelova, M. Novak, \& A. Mizerova (Eds.), Forgotten times and spaces: new perspectives in paleoanthropological, paleoethnological and archeological studies (pp. 347-360). Brno: Institute of Archeology of the Czech Academy of Sciences, Masaryk University.

Shirokov, V. N. (2018). Arte Paleolítico de los Urales. Nailos, 5, 133-148.

Shirokov, V. N., \& Petrin, V. T. (2013). Art of the Ice Age. In Ignatievskaya and Serpievskaya 2 caves in the Southern Urals. Ekaterinburg: Azhur (In Russian).

Sieveking, A.G. (2003). Groupes locaux et contacts à grande distance dans l'art paléolithique. Préhistoire, Art et Sociétés-BSPA, LVIII, 85-97.

Solodeinikov, A. K. (2019). Shulgan-Tash cave continues to share its treasures. http://npcrb.ru/peshherashulgan-tash-prodolzhaet-delitsya-svoimi-sokrovishhami.html. Accessed 28 Oct 2019. (In Russian).

Trimmis, K. P. (2018). Paperless mapping and cave archaeology: a review on the application of DistoX survey method in archaeological cave sites. Journal of Archaeological Science: Reports, 18, 399-407.

Vialou, D. (1986). L'art des grottes en Ariège magdalénienne. Gallia Préhistoire XX sup. Paris: CNRS.

Viggiano, M. P., \& Vannucci, M. (2002). Drawing and identifying objects in relation to semantic category and handedness. Neuropsychologia, 40, 1482-1487.

Zhitenev. (2015). Zoo-anthropomorphic image from Kapova cave and the hybrid wall drawings in FrancoCantabrian cave art. In Proceedings of the IV Northern Archaeological Congress, Government of KhantyMansiisk Autonomous Okrug-Ugra (pp. 237-240). Ekaterinburg: (In Russian).

Zhitenev, V. S. (2016). The variety of forms of symbolic and domestic practices in the Shulgan-Tash (Kapova) cave space. In Ancient sanctuaries: archaeology, ritual, mythology. Materials of International scientific Symposium (pp. 79-93). Ufa: Institute for History Publishing house.

Zhitenev, V. S. (2018). Kapova cave - Paleolithic underground sanctuary. Moscow: "Indrik". (In Russian). Zhitenev, V. S., Pakhunov, A. S., Margarian, A., \& Soldatova, T. E. (2015). Radiocarbon dates of Upper Paleolithic layers of Kapova cave (the Southern Urals). Rossijskaia Arheologija, 4, 5-15 (In Russian).

Publisher's Note Springer Nature remains neutral with regard to jurisdictional claims in published maps and institutional affiliations. 